\title{
Informed consent in evaluation: informed of what, exactly?
}

\begin{tabular}{c}
\hline Emma Williams \\
Northern Institute \\
Charles Darwin University \\
emma.williams@cdu.edu.au \\
\hline
\end{tabular}

Keywords: informed consent, evaluation ethics, evaluation informed consent, front end review, back end risk, layered power

\begin{abstract}
Australia's 2007 National Statement on Ethical Conduct in Human Research includes a requirement for informed consent from research participants. This paper discusses how the dynamics of bio-medical research, which underlie the national statement and processes aligned to it, differ from the dynamics often encountered by researchers conducting program evaluations with particular reference to two areas: the multiple layers of power that interact in a typical program evaluation, and the risks experienced by evaluation stakeholders in the late stages of the process. Implications for informed consent in evaluations are outlined and future steps proposed.
\end{abstract}

\section{Introduction}

This paper examines areas in which the ethics of evaluation differ from the ethics of other types of research, focusing particularly on 'informed consent'. The paper demonstrates how the context of evaluation impacts on calculations of risk and benefit, and why 'informed consent' may need to be re-conceptualised for evaluators.

The emphasis here is not on personal ethics, although they are acknowledged as vital for ethical practice. Rather, the focus is on how the dynamics of evaluative research present challenges to the way that 'informed consent' is regarded in ethics review committees' decision-making aligned to Australia's National Health and Medical Research Council's National Statement on Ethical Conduct in Human Research (NHMRC, 2014e). The National Health and Medical Research Council (NHMRC) procedures and forms were developed originally to assess biomedical risks and later extended to social science research, with a recent document focusing on quality assurance and evaluation activities (NHMRC, 2014b). 
Although the extension of medical ethics procedures to research in other fields was driven first in America (Ticheloven \& Willems, 2013), it has since occurred in many countries around the world. Social scientists in a number of countries including Australia, Canada and England have raised the issue of disparities between medical research approaches and those used in other fields, noting that the risks and benefits of their research were not sufficiently well recognised by committee deliberations aligned to bio-medical research models (e.g. Israel, 2004: Social Sciences \& Humanities Research Ethics Special Working Committee, 2004; Calvey, 2008; Hammersley, 2010; Academy of Social Sciences, 2013).

Although consultation continues to occur with a range of social scientists as well as other researchers (e.g. NHMRC, 2014a) and progress has been made in addressing some concerns (e.g. Zimmerman, 2013), less attention has been paid in the past to the ethics of evaluation (Berends, 2007; Chesterton, 2003).

A recent initiative to address issues associated with ethical conduct of evaluations was the NHMRC's Ethical Considerations in Quality Assurance and Evaluation Activities released in March 2014. It noted that, 'Human Research Ethics Committee (HREC) review processes are often not the optimal pathway for review of these [evaluation and quality assurance] activities' (NHMRC, 2014a, p. 1). Although identifying higher risk criteria such as the use of placebos and control groups, the document focuses on quality assurance and evaluations relying solely or in large part on the analysis of existing data rather than requiring research with human subjects/participants.

While some evaluations are undertaken without undertaking research activities with human participants, this paper focuses on those that do. It identifies ethical issues which distinguish research in the context of evaluation of social programs and interventions from many other forms of research involving human participants, with special emphasis on what is required for informed consent.

\section{Background}

While ethical decision-making has been discussed for centuries, many of the current guidelines and regulatory mechanisms encountered by evaluators and other researchers took shape after the Second World War. Revulsion at Nazi-auspiced medical abuse led to the Nuremberg Code in 1947, followed by the Declaration of Helsinki on ethics for human experimentation issued in 1964, and since updated a number of times. Intended to be an international guideline rather than a legally binding document, not every country has agreed to all aspects of the most recent version of the Declaration (World Medical Association, 2013). However, many countries have issued their own codes and guidelines that include mechanisms for local enforcement.

In some cases, these were driven by medical and/or social science research scandals. Making research funding contingent on the approval of independent ethics review committees, in the form of Institutional Review Boards, was initiated in America in the 1970s in part due to the Tuskegee syphilis research project (Heintzelman, 2003). The 
Tuskegee study used approximately 400 African American men as a control group and did not inform participants of remedies that were increasingly identified as effective for their illness over the course of the study, resulting in unnecessary deaths.

Social science research projects in the 1960s and early 1970s also raised serious ethical issues (Ticheloven \& Willems, 2013). Two American studies often cited as bringing about greater ethical oversight were the Milgram experiment (Milgram, 1963) and the Humphreys (1970) 'tearoom trade' project. The Milgram experiment deceived participants into believing they were delivering painful electric shocks to other participants. In Humphreys' 'tearoom trade' project, he copied the licence plate numbers of men frequenting public toilets for sexual encounters and then tracked some to their homes, later interviewing them as a social health surveyor on topics such as their marital and occupational status.

Subsequent calls for such research to be reviewed by independent committees to ensure ethical practice led to the US National Research Act of 1974 (National Commission for the Protection of Human Subjects of Biomedical \& Behavioral Research, 1979) and the development of institutional review boards for non-medical research. The review boards were empowered to require researchers to submit research designs for approval before commencing. This "front end" process has since intensified in the degree of scrutiny mandated for such review, and has also been extended to a broader range of research fields. (See Hammersley, 2010 for a somewhat vituperative discussion of this phenomenon.)

Australia has followed these precedents, although the development of Australian ethical regulatory mechanisms appears less scandal driven.

Before...1985, ethical issues in social and behavioural research were recognised by Australian associations in sociology, psychology and anthropology, who offered guidance to their members on the ethical conduct of research... NHMRC extended the jurisdiction of IECs [Institutional Ethics Committees, the precursors to Human Research Ethics Committees] to include non-medical projects in $1986 \ldots$ [reflecting] the shifting ground of health care delivery... As research institutions began to implement the requirements for... behavioural health research, many extended the requirements of the NHMRC to other types of social and behavioural research. In addition, funding bodies began to require approval by an IEC as a condition for considering social science grant applications in areas related to health or health care (NHMRC, 2014c).

Further development has occurred in the decades since, although there is not enough space here to address it in detail. Working together, the Australian Health Ethics Committee, the Australian Research Council and the Australian Vice-Chancellors Committee conducted consultations with institutions and researchers to produce the 2007 National Statement on Ethical Conduct in Human Research, with an updated version released in 2014 (NHMRC, 2014e).

Consultation and further development is continuing (NHMRC, 2014a), with a new distinction proposed between activities that are relatively 'low risk' and could benefit 
from a less onerous process than that required by higher risk research, similar to the 'light touch review' noted in the UK Research Ethics Framework (Economic \& Social Research Council, 2012). Evaluation has been identified by NHMRC as an area of relatively low risk compared to research.

... QA [Quality Assurance] and evaluation commonly involve minimal risk, burden or inconvenience to participants, and, while some level of oversight is necessary, Human Research Ethics Committee (HREC) review processes are often not the optimal pathway for review of these activities. (NHMRC, 2014b, p. 2)

The relationship between 'evaluation' and 'research' has been explored from multiple perspectives in the literature, (e.g. Levin-Rozalis, 2003; Fain, 2005). Rogers (2014) sets out four ways in which the relationship has been conceived:

- Research and evaluation may be seen as dichotomous, and the differences between them emphasised.

- Evaluation and research may be seen as mutually exclusive domains with an area of potential overlap where systematic data collection and analysis are the basis of evaluative judgments.

- Research may be seen as a subset of evaluation in that evaluations involve research, but also other types of activity.

- Evaluation may be seen as a subset of research as it is only one of many ways of investigating questions and reporting findings.

Rogers notes that these perspectives need not be mutually exclusive, and the choice of which perspective to employ will depend upon context.

Although Ethical Considerations in Quality Assurance and Evaluation Activities (NHMRC, 2014b) notes that Quality Assurance, evaluation and research can be seen as "a continuum of activity" (NHMRC, 2014b, p. 2), overall the document appears to treat evaluation and research as largely mutually exclusive domains, with a limited degree of overlap. As noted above, this paper addresses evaluations which fall into that area of overlap.

After an overview of requirements for informed consent, the paper looks at how the social science research is impacted by an ethical review process based on a biomedical research model. A section on the special dynamics of evaluation leads to one specifically on informed consent in evaluation, what is required for it and the degree to which it is addressed in current ethical guidelines.

\section{Informed consent}

Informed consent lies at the heart of research ethics. The 1947 Nuremberg Code begins:

The voluntary consent of the human subject is absolutely essential... the person involved should have... sufficient knowledge and comprehension of the elements 
of the subject matter as to enable him to make an understanding and enlightened decision. (Carlson, Boyd \& Webb, 2004, Appendix 1, paragraph 2)

Multiple versions of the Helsinki Declaration state that an individual's right to decide whether or not to participate takes precedence over the benefit of increased scientific knowledge. This precedence is not absolute; all ethical decision-making requires potential benefits to be balanced against potential risk, but what Sleat (2013, p. 15) calls the 'participant protection model... is at the heart of the ethical regulation of the biomedical sciences and... has often either influenced or been directly imported as the model for thinking about similar regulation of the social sciences'1.

Informed consent is not an issue reserved for research; Skene and Smallwood (2002) note that medical practitioners are now expected to provide patients with an increasing range of information, including more details on outcomes such as possible side effects of treatment.

Courts in Australia and England have begun applying a tougher standard to the information that doctors should give their patients... recent judgments in both English and Australian courts suggest that judges are moving away from accepting what "reasonable doctors" might do to supporting what "reasonable patients" might expect. (Skene \& Smallwood, 2002, p. 39)

While medical practitioners might once have been reluctant to share information that might distress patients and therefore be regarded as causing them harm, the trend now is towards providing all available information, to enable patients to better understand their options.

In research, what is required for fully informed consent is that 'there must be full disclosure of the purpose to which the research will be put, the nature of the information sought from the participant, and the motivations of the researcher in seeking this particular information' (Sleat, 2013, p. 16). The Australian National Ethics Application Form (NHMRC, 2014d) asks: if consent will be sought from all participants; if they have capacity to give consent, and what mechanisms, assessments and tools will be used to determine capacity to give informed consent; how participants will be informed about the project and choose whether or not to participate; and whether there are consequences to non-participation or later withdrawal. Answering such points may seem simple, but Wiles, Crow, Charles and Heath (2007) note:

While at first glance informed consent appears a relatively straightforward issue involving the provision of appropriate information to enable people to make informed decisions about participation in a research project, a closer examination of the issues involved reveals that the process is far from straightforward... (Section 1.4)

Issues identified in Wiles et al. $(2005,2007)$ include: a lack of consensus about what comprises 'informed consent'; whether the concept is or should be the same across different fields of research and methodological frameworks; the tension between providing adequate information and overloading potential participants with so much 
information they cannot absorb it; and the factors that affect participants' desire to engage with information (including format of presentation, language and literacy factors but also interest in the topic and a consequent reluctance to fully engage with discussion of risk factors). One of the most difficult issues is deciding how much information to provide on possible research outcomes, especially as these may not be known until the research has progressed substantially. Heintzelman, discussing a biomedical project, notes:

The first major ethical issue to be considered is informed consent, which refers to telling potential research participants about all [emphasis added] aspects of the research that might reasonably influence their decision to participate. A major unresolved concern is exactly how far researchers' obligations extend to research subjects. (Heintzelman, 2003, para. 6)

A recent book on ethics in evaluation also emphasises the value of voluntary consent. One of the most famous ethical formulations is 'first, do no harm', often popularly although erroneously attributed to Hippocrates (Sokol, 2013). However, as Morris notes in writing about evaluation ethics, the principle of non-maleficence or 'do no harm' is placed second in priority in a hierarchy of five ethical principles for helping professions (Morris, 2008). The first principle was 'respect for autonomy', which underlies informed consent ${ }^{2}$. With 'respect for autonomy', Morris notes, 'an evaluator's desire to collect information... does not necessarily [sic] override someone else's right not to provide some or all of that information, depending on the circumstances'.

Informed consent is a required element in the institutional review of research ethics in Australia, conducted by Human Research Ethic Committees aligned to the National Statement on Ethical Conduct in Human Research (NHMRC, 2014e). The current model used at many Australian research institutions requires researchers to fill out forms, with an on-line version available (NHMRC, 2014d), which asks them to 'Describe the consent process, ie how participants or those deciding for them will be informed about, and choose whether or not to participate in, the project' (2014d, 6.6.1.1.3).

The informed consent question - including procedures for obtaining (and documenting) informed consent - is embedded in a longer form, which also requires researchers to provide information on:

- the research project title and description;

- who will undertake the research, their qualifications and training

- funding/support for the project;

1. There is no space here to discuss how ethical theories such as principlism, consequentialism and utilitarianism, deontology and virtue ethics, and the ethics of care have impacted on such developments. However, see Carpenter, 2013; Simons, 2006; Treasury Board of Canada Secretariat, 2006, for examples.

2. The final three, in descending order of priority were: 'beneficence'; 'justice', which included both procedural and distributive fairness; and 'fidelity', i.e., keeping commitments to people. 
- any previous reviews;

- the type of research proposed, research plan, risks and benefits identified, andhow monitoring will be done;

- a description of participants, how they will be recruited and their consent requested, followed by a section on participants with specific vulnerabilities

- confidentiality and privacy issues; and

- in a final section, more detailed questions for certain types of projects - most medical, but also including workplace research, overseas research, and research involving Aboriginal and Torres Strait Islander participants.

The answers provided by the researcher(s) go to a committee where they are reviewed and comments made. The time required for this can be substantial, particularly in institutions where committees meet at relatively infrequent intervals. Typically no member of the research team is present at the review; reviewers' comments are provided in writing, and the researcher(s) have to respond to identified concerns before the project can advance.

\section{Ethics review and social science research}

Where evaluation is seen as a subset of research, it is typically viewed as a subset of social science research; evaluations of social programs and interventions commonly involve social science research methods. As well as analysing existing program/ service data, evaluators often collect new data through a range of social science research methods tailored to the research being undertaken (e.g. surveys, focus groups, interviews, projective techniques, observational methods including participant observation techniques, etc.). The appropriate technique often depends upon the topic; for example, criminological evaluations tend to use the techniques of criminological research.

The relationship between social science and bio-medical research ${ }^{3}$ has been widely discussed, including the effect on social science research of institutional review mechanisms originating from bio-medical models. Van den Hoonard (2013) notes, for example that since 2000, an average of ten publications a year have discussed the difference between biomedical and sociological paradigms. He states that 'the biomedical paradigm offers nothing that might be even remotely helpful to sociologists in their search for ethics in research' (2013, p. 23).

Van den Hoonard's views are more extreme than many others. Some note improvements have occurred within the past decade. In 2004, a working committee of those working in the humanities and social sciences in Canada stated:

If there is a fundamental problem we can identify, it is that the granting agencies' desire to create a regulatory structure to deal with the stereotypical clinical trial 
has resulted in a document and set of structures that assume different modes of research involving different relationships and different concerns than most social science and humanities researchers seek and encounter. (Social Sciences \& Humanities Research Ethics Special Working Committee, 2004, p. 10)

Informed consent in particular was noted as an issue:

Informed consent is a universally important component of respect for the autonomy of research participants, but the approach to consent in the present TCPS [TriCouncil Policy Statement: Ethical Conduct for Research Involving Humans] is narrowly conceived and does not fit many modes of inquiry in the social sciences and humanities. SSHWC [the Social Sciences and Humanities Research Ethics Special Working Committee] recommends the idea of consent (and default expectations about the way it is obtained) be considered further, with a view to making the TCPS better include and reflect the diversity of ethical relationships between researchers and participants. (Social Sciences \& Humanities Research Ethics Special Working Committee, 2004, p. 6)

However, by 2013, a Canadian representative was able to assure social scientists that the 2010 version of the Tri-Council Policy Statement: Ethical Conduct for Research Involving Humans (TCPS2) incorporated changes based on social scientists' critiques and was now more responsive to research approaches in multiple disciplines (Zimmerman, 2013).

Other social scientists have pointed out the positive benefits of ethics review, with Hunter (2013) stating that 'ethical review forms are one of the few [administrative] processes that I actually find helpful, that provoke me and my students to be better researchers... (2013, p. 19). Nevertheless, Hunter finishes her sentence by noting that the review board may obstruct certain types of research, a theme echoed by other researchers (e.g. Wynn, White, Thomson \& Israel 2013). Concerns raised by social scientists to ethics review by institution review boards also include:

3. The National Health and Medical Research Council, as attested by its name, focuses primarily on bio-medical research risks and benefits, although many other forms of research are subject to its forms and procedures for approval. A recent document (NHMRC, 2014a) sets out five major categories of research:

- research infrastructure, i.e., establishing a biobank or database;

- health research;

- clinical research with four sub-categories;

- laboratory/basic science research including most genetic research; and

- one category that lumps together all other forms of research, listed in the document as 'Arts, Social sciences, Humanities, Business, Education, Law, Engineering and Computing' research (NHMRC, 2014b, p. 8). 
Regulated mandatory review is not needed and may itself be unethical

Some see ethics review boards as being more about minimising institutional risk than ensuring ethical research, and want to see discussion of ethics separated from practical concerns about 'risk' (Emmerich, 2013, p. 12) and a 'more discursive encounter between researcher and reviewer/committee' (Emmerich, 2013, p. 13). Others object to the very notion of ethical regulation:

My view is that any form of ethical regulation in this context [author emphasis retained, speaking of social science research as the context] is itself unethical, because it damages the quality of research and infringes the legitimate autonomy of researchers, without there being any counterbalancing need for it (the situation is different in some areas of medicine). (Hammersley, 2013, p. 6)

\section{‘Front end' reviews do not work well for much social science research}

As noted above, ethical systems with bio-medical origins, such as the current NHMRC ethical review process, are 'front loaded', i.e., approval is given at an early stage of the project and typically required before the project can formally begin. Research questions, forms and procedures are expected to be developed before the research commences. As noted regularly in the literature, much social science research is dynamic and contingent, with the research model evolving over the course of the study (e.g. Calvey, 2008). Participatory and empowerment methodologies particularly struggle with 'front end' ethical review, as in these approaches the research design and even evaluation questions emerge from the research, rather than being pre-determined. (See Simons, 2006, for more on this issue.)

\section{'Risk' and 'power' in social science contexts differ from bio-medical contexts}

There are substantial differences in risk and power between medical and social science research contexts. A clinical study, for example, typically involves people who have come to a medical practitioner seeking help because the practitioner has expert professional knowledge they do not have, and medical treatments such as new drugs being tested can pose genuine physical risks. In such situations, with such vulnerable participants, asymmetry of knowledge/power, and risks of worsening health or even death, strict guidelines are essential.

However, in social science contexts, 'in the vast majority of studies the potential for causing physical harm to the participants is clearly lower than in biomedical sciences' (Sleat, 2013, p. 16). Social science risks are more commonly ones of inconvenience with potential in some cases for participant stress or offence, and in particularly severe cases harm to reputation. (These are, of course, still worthy of concern.)

Similarly, there is generally much less asymmetry in power - it is relatively common for social scientists, in fact, to seek to research those with greater power than the 
researchers, if not as individuals, then because of their role, such as holding public office (Boyd, 2013). Sleat similarly notes that in the social science research context 'it is the researcher who is often in the weaker position and the participant in a position to potentially harm' $(2013$, p. 16).

\section{More discipline-specific committees are required}

Some authors point out the importance of discipline-specific committees, noting that committee members may struggle with calculating the relative risks and benefits of research in areas unfamiliar to them.

Criminological research provides a good example, as it poses special challenges such as dealing with illegal activities; real expertise is required to accurately understand how risks can be managed and benefits realised. With regard to criminological research techniques which have been well established over decades, Israel (2004) notes that some Australian ethics review committees 'seemed to overestimate both the magnitude and the probability of risks' (p. 65), with some seeking to reject techniques well-accepted by research committees overseas. Israel notes that criminology-specific committees perform better in this area.

\section{The special dynamics of evaluation}

Evaluators conducting program evaluation requiring research contact with human participants share many of the issues of social science researchers.

The 'front end' ethics review process, where research questions are expected to be formulated before going into field, does not align well with the frequent use by evaluators of program logic, program theory and other processes where research questions are formulated and refined through engagement with participants and stakeholders. Many other evaluators use participatory and empowering approaches which, as noted above, are not well suited to a 'front end' approach. Some types of evaluation approaches such as 'developmental evaluation' (Patton, 2010), designed to be applied in contexts where programs are constantly evolving in response to dynamic contexts, face special challenges in complying with a 'front end' approach.

However, these are relatively minor issues compared to other aspects of evaluative research. Rogers (2014) notes in her "dichotomous" view of evaluation and research that research 'is seen as... more controlled by the researchers - evaluation is seen as... more controlled by those funding or commissioning the evaluation' (Rogers, 2014, section 1, para. 1). Similarly, Michael Quinn Patton notes that typically in research, questions 'originate with scholars' and the research 'quality and importance [are] judged by peer review', while in evaluation 'questions originate with key stakeholders and primary intended users' with 'quality and importance judged by those who will use the findings to take action and make decisions' (2014, section 5). 
This means, for example, that the researcher who fills out the forms for the Human Research Ethics Committee may well be constrained in research design and timing by the dictates of the evaluation 'commissioner', who may or may not have much research or evaluation experience and expertise. The ethical dilemmas this places on evaluators have been cited quite widely in the evaluation literature, including Scougall, 2006; Roorda and Peace, 2009; Williams, Guenther and Arnott, 2011.

Another issue is that often the time allowed for the project to go into field is truncated relative to other types of research (Scougall, 2006; Roorda \& Peace, 2009, Guenther, Williams \& Arnott, 2010), so there is often pressure to go through the ethics process quickly or avoid it altogether. This has sometimes resulted in academic institutions withdrawing from responding to opportunities to undertake evaluations, because the time given to undertake the evaluation and submit the final report is insufficient to go through an institutional board ethical review process, or because the time frame for the research appears in itself unethical (Williams et al. 2011).

Part of the dilemma is that while evaluators can be considered to have a degree of power with regard to evaluands (i.e., evaluation subjects, participants), in many cases evaluation commissioners have a degree of power with regard to evaluators. As Simons (2006) notes:

Evaluation involves at least four levels of social-political interaction - with government and other agency policy makers who commission evaluation; with participants in the programmes, policies and institutions evaluated; with the evaluation profession; and with the wider audiences to whom evaluators in a democratic society have a responsibility to report. Evaluation has to operate in this multilayered context of different interests... it is not surprising that ethical dilemmas arise... (p. 213)

Morris (2008) cites a useful distinction between 'ethical dilemmas' and 'mixed dilemmas'. For Morris, 'ethical dilemmas' require an evaluator to balance conflicting principles, such as respecting individual confidentiality versus providing information for public benefit. It can often be difficult to decide in such circumstances what course of action is most ethical. 'Mixed dilemmas', on the other hand, require an evaluator to maintain an ethical principle in the face of external pressure to abandon it. The example given by Morris is an evaluator being pressured by a stakeholder to write up more positive results for a program that are warranted by the evidence.

It is usually clear to the individual in a mixed dilemma what it is, from an ethical perspective, he or she should do. The problem is that the ethical course of action is often a risky course of action for that individual. The evaluator who refuses to bend in response to stakeholder pressure for positive results might find him- or herself the target of a subtle (or not so subtle) smear campaign waged by the aggrieved stakeholder... (Morris 2008, Chapter 1, third section)

Again, the evaluation literature contains many examples of such mixed dilemmas (e.g. Guenther, Williams \& Arnott, 2010; Markiewicz, 2008, 2010). A survey of Australian Evaluation Society members with 132 respondents (Turner, 2003) found that when 
members identified ethical challenges and dilemmas, they were very likely to be 'mixed dilemmas'. Those cited by Turner included:

- Managers or funders trying to influence or control evaluation findings, sometimes including pressure on evaluators for positive results (cited repeatedly), sometimes including pressure to provide "dirt" on a program

- Conflicts between the organisation's needs and those of the client (when working as an internal evaluator)

- Political interference

- Dissemination or suppression of reports

- Requests to use information gathered for one purpose (e.g. program improvement) for a different purpose (e.g. accountability)

- Unilateral changes to terms of reference midstream or at time of reporting an evaluation and dealing with the implications for quality and relevance of data collected. (2003, para. 5)

As Markiewicz (2008) notes, pressure may be applied to make more positive reports, or alternatively to make a negative report on a program even where the evaluator's evidence indicates that the program is achieving successful outcomes. The pressure applied in these situations can be quite intense, with real implications for the evaluator's future work and income.

Moreover, the evaluator is not the only one to feel the impact of these decisions. Findings from an evaluation can lead to programs being renewed, reshaped, expanded or terminated. Particularly in tight economic environments, evaluation utilisation can result in the loss of jobs and the withdrawal of community services, with both staff and program clients impacted.

Further, evaluators can be pressured to not reveal findings to participants, e.g. Williams 2011. In 2010, a workshop held by the Australasian Evaluation Society (Markiewicz, 2010) in New Zealand elicited many cases from those attending of submitting positive reports on programs and services, but being forbidden to share them with the evaluation participants. The evaluators spoke of the participants' anger when their program or service was terminated, assuming the evaluator must have submitted a negative report. Workshop participants noted the degree to which this poisoned the relationship between evaluators and participants, damaged trust, and created a toxic environment for future research work. (This type of impact, i.e., spoiling the potential

4. A term often used in Australia to denote the person or agency contracting/commissioning the evaluation. 
for future research and lessening community trust in researchers, was one of the issues that led to the current system of institutional ethics review after projects such as Humphreys' (1970) and Milgram's (1963) research, as discussed above.)

Importantly, these risks tend to occur at the 'back end' of the evaluation research process. Forms and procedures developed from a bio-medical model of research focus on risks incurred during the data collection stage, and consider issues such as potential participant burden during that stage; even social science research echoes this pattern. However, in many evaluations, the most important risks often come for the evaluator at the reporting stage of the evaluation, and for participants and community members at the utilisation stage.

Not all ethics review committee members may be familiar with the special dynamics of much contracted program evaluation, hence Berends' (2007) proposed training and initiatives in this area. Reviewers working within a 'front end' system based on bio-medical research models could struggle particularly in two areas: recognising the risks that may be incurred after data collection and analysis has been completed, and understanding the special role of the evaluation commissioner. As Chesterton notes:

To what extent could or should the commissioner of an evaluation be able to control the nature and focus of an evaluation? In one sense, the answer to this latter question is quite clear - the purchaser decides what he or she will purchase and spends accordingly. When this is put into a broader context of consequences, duties, obligations, rights, justice, and care, involving a range of stakeholders as well as the commissioner and the evaluator, and the use of public money, the answer is not so clear. (2003, p. 57)

Given these dynamics, what are the implications for informed consent in evaluation?

\section{Informed consent in evaluation}

Calvey notes that an issue faced by social science researchers is "what I refer to as the 'consent to what' problem, in that social research is often contingent and all probabilities cannot be covered by the consent form' (Calvey, 2008, p. 907). This problem is particularly acute in evaluation. What exactly is the 'what' that evaluation participants need to understand before they can provide informed consent?

For example, as noted by Patton (2014) above, one of the differences between 'evaluation' and 'research' (when taking a dichotomous view of their relationship) is that evaluation informs decisions. If the decision-making stage is considered an integral part of the evaluation, should human research ethics committees require it to be discussed with participants in securing their informed consent? Should informed consent extend to information about potential participant risks related to the utilisation stage - taking into account that this stage is not under the control of the researcher/ evaluator and utilisation decisions typically cannot be predicted too far in advance? 
As many risks of become evident only as the evaluation progresses, Simons (2006) has proposed "rolling consent":

Gaining informed consent is an ethical imperative in any research study and signing an informed consent form is a familiar formal procedure in many contexts. Yet for many [in evaluation contexts] this is not consent at all, as it is never possible to know what will transpire as the programme unfolds in a precise socio-political context. Whatever forms are signed, "free and fully informed consent" needs to be realized through the additional different procedure of "rolling consent" renegotiating consent with each person and/or site once a greater awareness of the context and structure of the study is known... (p. 26)

How does this notion align with current institutional ethics review procedures? Also, a critical aspect of voluntary consent is the capacity of the participant to withdraw from the research. Given the risk to participants may only become apparent at the end stage of evaluations, at the submission and utilisation stages, what are the realistic options for participants to withdraw at that point? How should evaluators deal with identifying and taking out perspectives which may by that time have permeated much of the report document? While it is certainly possible to take out specific sentences, it would be disingenuous to claim that all of the knowledge gained could be forgotten.

Finally, how do evaluators practise the ethical principle of 'fidelity' to their commitments to vulnerable stakeholders in a context where external parties wield such power, particularly in the later stages of the evaluation, such as submission (typically involving final payments to the evaluators) and reporting?

At the very least, it seems that the information required to ensure fully informed consent by evaluation participants would include reference to contextual factors, including identifying the evaluation commissioner and the evaluation questions, the potential outcome of the evaluation and particularly the likelihood of its utilisation by others for decision-making. This information would have to be updated over the course of the evaluation.

\section{Professional evaluator guidelines}

Such issues are not always - or even often - addressed in evaluators' professional codes and guidelines. In spite of some early aspirations (Keith, 2003), no international code of evaluation ethics has yet been developed, although a burgeoning of national and regional evaluation societies, associations and networks around the world led in 2012 to the development of the International Organization for Cooperation in Evaluation (Kosheleva \& Segone, 2013). Most national or regional guidelines focus on other aspects of professional practice and refer only obliquely to participant consent. Three sets of professional guidelines, however, are relevant, those of the United Kingdom Evaluation Society, the American Evaluation Association and the Australasian Evaluation Society guidelines. 
The United Kingdom Evaluation Society's Guidelines for good practice in evaluation address many aspects of participant consent in considerable detail, although the term is not mentioned explicitly. The guidelines require that participants get an explanation of the purpose and methods of the evaluation, how data will be checked, stored and disseminated, including the right to see the evaluation agreement before the evaluators access the programme. The guidelines also require that participants have opportunities to discuss and question issues with the evaluators, with independent arbitration in cases of disputes. However, these guidelines are aspirational suggestions on the United Kingdom Evaluation Society (UKES) website. Members are not required to be bound by them, and there are no sanctions within the UKES for not following them.

The American Evaluation Association (AEA) guidelines refer specifically to informed consent.

Evaluators should abide by current professional ethics, standards, and regulations regarding risks, harms, and burdens that might befall those participating in the evaluation; regarding informed consent for participation in evaluation; and regarding informing participants and clients about the scope and limits of confidentiality. (AEA, 2004, p. D2)

Other aspects of the American guidelines provide more guidance in aspects of informed consent relevant to evaluation, noting that evaluators should seek a 'comprehensive understanding of the important contextual elements of the evaluation [including] timing, political and social climate, economic conditions... (AEA, 2004, p. D1). The relationship to the evaluation commissioner is also noted:

... Evaluators necessarily have a special relationship with the client who funds or requests the evaluation... that relationship can also place evaluators in difficult dilemmas when ... client interests conflict with the obligation of evaluators for systematic inquiry, competence, integrity, and respect for people. In these cases, evaluators should... determine whether continued work on the evaluation is advisable... (AEA, 2004, p. E4)

As with the UK guidelines, there are no penalties proposed for those who do not follow them; the American Guiding Principles are meant to guide rather than constrain members' activities. In contrast, the Australasian Evaluation Society Inc. (AES) notes on its website that:

In deciding to become a member of the AES you are committing to two things:

- to abide by the AES Code of Ethical Conduct, and

- to support the AES Guidelines for the Ethical Conduct of Evaluations. (downloaded July, 2014)

Both documents were recently updated, and two points from the updated Guidelines for the Ethical Conduct of Evaluations (2013b) relate to informed consent:

Point 11. Evaluators should identify themselves to potential informants or respondents and advise them of the purpose and use of the evaluation ${ }^{5}$ and the identity of the commissioners of the evaluation. 
Point 12. The informed consent of those directly providing information should be obtained, preferably in writing. They should be advised as to what information will be sought, how the information will be recorded and used, and the likely risks and benefits arising from their participation in the evaluation. In the case of minors and other dependents, informed consent must be sought from parents or guardians.

The updated documents were intended to be only the first stage in revising the ethical guidelines; interactive materials were to be added to the website, including vignettes (see Desautels \& Jacob, 2012; Morris, 2008 for examples) and case studies similar to those elicited at the Wellington workshop. It was intended that the issues identified in this paper would be addressed in the vignettes and case studies. Although staffing and resource changes have stalled the development of these additional resources, the guidelines that do exist are binding on AES members, with potential for sanctions if complaints are made about them not being followed.

In Australia, there is some degree of direction for the hundreds of Australian members of the Australasian Evaluation Society on the importance of securing participant consent and what is required for it. How is this complemented by the informed consent requirements of Human Research Ethics Committees in Australia?

\section{NHMRC guidelines on research and evaluation}

As noted above, consent in the forms used by the NHMRC, such as the online National Ethics Application Form (NHMRC, 2014d), deals with issues such as ensuring participants understand the risks and obligations imposed by participation, and also understand that participation is voluntary. Potential payments, obtaining consent for minors and dependents, and other related issues are also covered. Except in rare, defined instances, researchers are expected to obtain the informed, voluntary consent of participants for all aspects of the research. The National Statement notes that: 'The ethical and legal requirements of consent have two aspects: the provision of information and the capacity to make a voluntary choice' (NHMRC, 2014e, p. 12). However, a recently released document dealing specifically with quality assurance and evaluation notes that 'importantly, QA and evaluation commonly involve minimal risk, burden or inconvenience to participants' (NHMRC, 2014b, p. 2). The document notes that evaluation 'is undertaken to generate outcomes that are used to assess and/or improve service provision' (NHMRC, 2014b, p. 2) and, citing the Australian Evaluation Society (2010) Guidelines, defines evaluation as:

... a term that generally encompasses the systematic collection and analysis of information to make judgements, usually about the effectiveness, efficiency and/ or appropriateness of an activity. The term is used in a broad sense to refer to any set of procedures, activities, resources, policies and/or strategies designed to achieve some common goals or objectives. (2014b, p. 2)

5. This may of course change over the course of the evaluation, and continued updates may well be required. 
While stressing the need to ensure that participants need to be protected from physical, spiritual, social harm and distress, and have mechanisms to voice concerns, the document offers advice on 'opt out' procedures, 'a method used in the recruitment of participants into an activity where information is provided to the potential participant regarding the activity and their involvement and where their participation is presumed unless they take action to decline to participate' (NHMRC, 2014b, p. 3). Due to the low risk nature of evaluation, it is noted that rather than going through the usual Human Research Ethics Committee procedures, ethical decision making for evaluation projects can be delegated to an HREC Chair, individual member or sub-committee, or to a special 'low risk committee' (NHMRC, 2014b, p. 4).

\section{Conclusion}

Informed consent is recognised as a cornerstone of ethical research practice. Although the NHMRC defines evaluation as generally 'low risk' (NHMRC 2014b), this paper has presented a view that the consequences of evaluation involving human research present a number of risks different to those incurred in (other) research. While most research ethics are designed to protect participants against risks incurred at the data collection stage, e.g. receiving a new drug or participating in a social science investigation, evaluative risks tend to occur at the 'back end' of the evaluation process, subsequent to the data collection stage.

The context of program evaluation is - not always, but more often than not - that it is contracted by someone who pays the evaluator and receives the evaluation findings as evidence for decision-making. This context leads to four layers of risk. Evaluators typically report particularly high risk at the report submission stage, with pressure (from a minority of commissioners ${ }^{6}$ ) to alter findings in ways not warranted by the evidence. Participants, on the other hand, may experience greater risks at the utilisation stage, as dissemination decisions are made and as changes are made to programs and services. For program staff, this stage can include changes in employment, including job loss. The next 'layer' at risk comprises program/service recipients, even if they were not evaluation participants whose informed consent was sought or required. They are affected by changes in operation, and sometimes by the termination of the service or program they had been accessing. Finally, some of the practices noted above - i.e. evaluation commissioners/finders requiring evaluators not to let participants know of positive evaluation findings and then terminating the program - can result in a long term lack of trust at the wider community level, with resistance to future research and evaluation.

In this context, the NHMRC document classifying evaluation as 'low risk' and generally not requiring a full Human Research Ethics Committee (HREC) review provides an opportunity to deal with evaluative risks more appropriately and expeditiously. One of the issues raised above, the difficulty of reconciling the time required for HREC review with the frequent need to get evaluations designs approved quickly, is resolved. The option of an alternative mechanism for ethical approval also offers opportunities to address the special risks posed by evaluation, which differ from bio-medical risks but 
also from the risks posed by other forms of social science research. Considering the four areas discussed above:

- Regulated mandatory review similar to that used for bio-medical research has been acknowledged by the NHMRC as less well suited to evaluation, perhaps partly in recognition that evaluation contract opportunities often cannot be approved through standard HREC processes in the time required.

- The 'front end' review process originating in bio-medical research contexts presents issues for social scientists due to the more dynamic and contingent nature of much social science research, as documented above, and evaluation shares that dynamic. However, the risks to social science participants typically arise in the data collection stage, as with bio-medical models, while risks to evaluation participants are often greater at the reporting stage and after the report has been submitted.

- 'Risk' and 'power' in social science contexts differ from bio-medical contexts, where there is often an asymmetry of power between researcher and research subject. Research participants in social science research may be possess equal or greater power than the researcher, and may pose risks to them. In evaluation, the agency commissioning/funding the project often possesses significant power.

- More discipline-specific processes may be enabled by the NHMRC determination that evaluation is 'low risk', and should be approved using different mechanisms than those used for bio-medical, social science etc. research.

With regard specifically to consent by evaluation participants, the minimum required to secure informed consent (as already noted above) would require the evaluator to provide potential participants with the identity of the evaluation commissioner, a list of the proposed evaluation questions (updated throughout the project as required), the potential outcome of the evaluation and particularly the likelihood of its utilisation by others for decision-making (again updated throughout the project as required).

However, unless the commissioning body is also willing to sign off on avoiding pressure to distort findings and/or to prevent them from being available to participants, fidelity to the requirements of informed consent will remain problematic. This is where the new NHMRC approach provides an opportunity for improved practice. Evaluation specific mechanisms could look at innovative approaches such as the more 'discursive' approach recommended by Emmerich (2013), involving both the evaluator(s) and the

6. It is worth noting that many evaluations are conducted without harm to the evaluator or participants. As in other forms of research, risk is calculated through a consideration of likelihood and consequence, and takes the minority of evaluations posing harm to evaluators and participants into account. Also, the Wellington workshop noted above indicates that the number of evaluations posing such risks are not insignificant. Further, it is worth noting that pressure on researchers to provide certain findings, or not to report others, is found in other forms of research, including some pharmaceutical research, defence research, etc., but it is a feature of much program evaluation. 
evaluation commissioner with the review committee or representative in discussing the ethics of the project. Discussions in this new model could address the importance of:

a. the commissioner not applying pressure to alter findings and produce conclusions not in accordance with the evidence; and

b. enabling evaluation participants to receive findings, at least in summarised form.

Such commitments would go a long way to ensuring truly informed consent in evaluation.

It is appreciated that this would be a departure from current practice, but it is hoped that this paper may lead to further dialogue with evaluation commissioners, users and evaluand representatives, as well as evaluation practitioners/researchers, to explore the issues of such an approach to evaluation ethics and informed consent in evaluation. In fact, it is even possible that if this approach proves successful, over time it may lead to changes in the ethical review of social science, bio-medical and other types of research.

\section{References}

Academy of Social Sciences. (2013, October). Generic Ethics Principles in Social Science Research, [Professional Briefings], Issue 03. Retrieved from http://acss.wpengine.com/wp-content/uploads/2013/11/pb3_ genericethicsprinciples.pdf

American Evaluation Association. (2004). Guiding Principles for Evaluators. American Journal of Evaluation, 27(3), [September 2006], pp. 293-294. Retrieved from http://www.samea.org.za/documents/AEA_guiding_principles_for_evaluators. pdf

Australasian Evaluation Society Inc. (2013a). Code of Ethics. Retrieved from http:// www.aes.asn.au/images/stories/files/membership/AES_Code_of_Ethics_web. pdf

Australasian Evaluation Society Inc. (2013b). Guidelines for the ethical conduct of evaluations. Retrieved from http://www.aes.asn.au/images/stories/files/ membership/AES_Guidelines_web.pdf

Berends, L. (2007). Ethical decision-making in evaluation. Evaluation Journal of Australasia 7(2): 40-45.

Boyd, K. (2013, October). Response (2) to 'Responsible to Whom? Obligations to Participants and Society in Social Science Research'. In Academy of Social Sciences (Ed.), Generic Ethics Principles in Social Science Research, [Professional Briefings], Issue 03, (pp. 20-22). London, UK: Academy of Social Sciences. 
Calvey, D. (2008). The Art and Politics of Covert Research: Doing 'Situated Ethics' in the Field. Sociology 42(5): 905-918.

Carlson, R., Boyd, K., \& Webb, D. (2004). The revision of the Declaration of Helsinki: past, present and future. Journal of Clinical Pharmacology 57(6): 695-713.

Carpenter, D. (2013, October). Generic Ethics Principles in Social Science Research Discussion 'Stimulus' Paper. In Academy of Social Sciences (Ed.), Generic Ethics Principles in Social Science Research. [Professional Briefings], Issue 03, (pp. 3-6). London, UK: Academy of Social Sciences.

Chesterton, P. (2003). Balancing Ethical Principles in Evaluation: A Case Study. Canadian Journal of Program Evaluation 18(1): 49-60.

Desautels, G., \& Jacob, S. (2012). The ethical sensitivity of evaluators: A qualitative study using a vignette design. Evaluation 18: 437-450.

Economic \& Social Research Council [ESRC]. (2012). Framework for Research Ethics 2010, revised September 2012 Swindon: ESRC. Retrieved from ESRC website http://www.esrc.ac.uk/_images/framework-for-research-ethics-09-12_tcm84586.pdf

Emmerich, N. (2013, October). Summary of Symposium 1. In Academy of Social Sciences (Ed.), Generic Ethics Principles in Social Science Research.

[Professional Briefings], Issue 03, (pp. 9-14). London, UK: Academy of Social Sciences.

Fain, J. (2005). Is There a Difference Between Evaluation and Research?. The Diabetes Educator 31(2): 150-155.

Guenther, J., Williams, E., \& Arnott, A. (2010). The politics of evaluation: evidencebased policy or policy-based evidence? Paper presented at NARU Public Seminar Series, Darwin.

Hammersley, M. (2006). 'Are ethics committees ethical?' Qualitative Researcher 2: 4. Retrieved from http://www.cf.ac.uk/socsi/qualiti/QualitativeResearcher/QR_ Issue2_06.pdf

Hammersley, M. (2010) 'Creeping Ethical Regulation and the Strangling of Research'. Sociological Research Online 15(4): 16.

Hammersley, M. (2013, October). Response (1) to 'Generic Ethics Principles in Social Science Research'. In Academy of Social Sciences (Ed.), Generic Ethics Principles in Social Science Research, [Professional Briefings], Issue 03, (pp. 3-6). London, UK: Academy of Social Sciences.

Heintzelman, Carol, A. (2003). The Tuskegee Syphilis Study and Its Implications for the 21st Century. Social Worker, 10(4). Retrieved from http://www.socialworker. com/tuskegee.htm 
Humphreys, L. (1970). Tearoom Trade: Impersonal Sex in Public Places. Chicago: Aldine Publishing Company.

Hunter, R. (2013) Response (2) to 'Responsible to Whom? Obligations to Participants and Society in Social Science Research'. In Academy of Social Sciences (Ed.), Generic Ethics Principles in Social Science Research, [Professional Briefings], Issue 03, (pp. 18-20). London, UK: Academy of Social Sciences.

Israel, M. (2004). Ethics and the governance of criminological research in Australia. NSW Bureau of Crime Statistics and Research, Attorney General's Department.

Israel, M. (2013). Rolling back the bureaucracies of ethics review. Journal of Medical Ethics 39(8): 525-526.

Keith, G. (2003). The Canadian Evaluation Society (CES) Experience in Developing Standards for Evaluation \& Ethical Issues. Paper presented in The 5th European Conference on the Evaluation of Structural Funds in Budapest, Hungary.

Kosheleva, N., \& Segone. M. (2013, December). EvalPartners: Facilitating the development of a new model of voluntary organization for professional evaluation to support the development of national evaluation capacities. American Journal of Evaluation, July 10, 2013, 34(4), pp. 568-572. Retrieved from http://dx.doi.org/10.1177/1098214013493656

Levin-Rozalis, M. (2003). Evaluation and research: Differences and similarities. Canadian Journal of Program Evaluation 18(1): 1-31.

Markiewicz, A. (2008). The political context of evaluation: what does this mean for independence and objectivity? Evaluation Journal of Australasia 8(2): 35-41.

Markiewicz, A. (2010). Can Evaluation be Politically Grounded, Policy Relevant, Participatory AND Objective and Independent? Australasian Evaluation Society International Conference, Wellington, New Zealand. September 2010, Retrieved November 2011 from http://aes.asn.au/conferences/2010/Presentations/ Markeiwicz,\%20Anne.pdf

Milgram, S. (1963). Behavioral study of obedience. Journal of Abnormal and Social Psychology 67: 371-378.

Morris, M. (Ed.). (2008). Evaluation Ethics for Best Practice: Cases and Commentaries. New York: Guilford Press.

National Commission for the Protection of Human Subjects of Biomedical and Behavioral Research (April 18, 1979). The Belmont Report: Ethical Principles and Guidelines for the protection of human subjects of research. [Regulations and Ethical Guidelines]. US Department of Health, Education \& Welfare. Retrieved from the US Department of Health \& Human Services website http:// www.hhs.gov/ohrp/humansubjects/guidance/belmont.html 
National Health \& Medical Research Council. (2014a). Building a new application form for use in human research: Consultation on the structure and content of the form. Draft document, May 2014. Retrieved from https://www.nhmrc.gov. au/_files_nhmrc/file/research/clinical_trials/discussion_paper_human_research_ application_form_may_2014_140606.pdf

National Health \& Medical Research Council. (2014b). Ethical considerations in Quality Assurance and evaluation activities. Retrieved from http://www.nhmrc. gov.au/_files_nhmrc/publications/attachments/e111_ethical_considerations_in_ quality_assurance_140326.pdf

National Health \& Medical Research Council. (2014c). History of ethics and ethical review of human research in Australia. Retrieved 7 July 2014, from http://www.nhmrc.gov.au/health-ethics/human-research-ethics/ history-ethics-and-ethical-review-human-research-australia.

National Health \& Medical Research Council, Australian Research Council \& Australian Vice-Chancellors' Committee. (2014d). National Ethics Application Form, Version 2.2. Retrieved from http://www.nhmrc.gov. au/health-ethics/human-research-ethics-committees-hrecs/hrec-forms/ neaf-national-ethics-application-for

National Health \& Medical Research Council, Australian Research Council \& Australian Vice-Chancellors' Committee. (2014e). National Statement on Ethical Conduct in Human Research 2007, (Updated March 2014). Retrieved from https://www.nhmrc.gov.au/_files_nhmrc/publications/attachments/e72_ national_statement_march_2014_140331.pdf

Patton, M. Q. (2010) Developmental Evaluation: Applying Complexity Concepts to Enhance Innovation and Use. Guilford Press, New York. Retrieved from http:// tei.gwu.edu/courses_approaches.htm\#developmental_evaluation

Patton, Michael Quinn. (2014). Evaluation Flash Cards: Embedding Evaluative Thinking in Organizational Culture. St. Paul, MN: Otto Bremer Foundation, ottobremer.org. Retrieved from http://www.ottobremer.org/sites/default/files/ factsheets/OBF_flashcards_201402.pdf

Rogers, P. (2014). Ways of framing the difference between research and evaluation: Better evaluation. Retrieved from Better Evaluation website (Week 19, May 9, 2014)http://betterevaluation.org/blog/ framing_the_difference_between_research_and_evaluation

Roorda, M., \& Peace, R. (2009). Challenges to implementing good practice guidelines for evaluation with māori: A pākehā perspective. Social Policy Journal of New Zealand 34: 73-89.

Scougall, J. (2006). Reconciling tension between principles and practice in Indigenous evaluation. Evaluation Journal of Australasia 6(2): 49 - 55. 
Simons, H. (2006). Ethics in evaluation. In I. F. Shaw, J. C. Greene \& M. M. Mark (Eds.), The SAGE Handbook of Evaluation (pp. 213-232). London UK, SAGE. Retrieved from http://www.uk.sagepub.com/gray3e/study/chapter12/Book\%20 chapters/Ethics_in_Evaluation.pdf

Skene, L., \& R. Smallwood. (2002). Informed consent: lessons from Australia. British Medical Journal 324(7328): 39-41.

Sleat, M. (2013, October). Responsible to whom?: Obligations to participants and society in social science research. In Academy of Social Sciences (Ed.), Generic Ethics Principles in Social Science Research, [Professional Briefings], Issue 03, (pp. 15-18). London, UK: Academy of Social Sciences.

Social Sciences \& Humanities Research Ethics Special Working Committee. (2004). Giving Voice to the Spectrum. Ottawa: Interagency Advisory Panel on Research Ethics. Retrieved from http://www.pre.ethics.gc.ca/english/workgroups/sshwc SSHWCVoiceReportJune2004.pdf

Sokol, Daniel K. (2013). First do no harm. [Revisited]. British Medical Journal 347:f6426

Ticheloven, A. \& Willems, M. (2013). The development of ethics in medical and social sciences in the last half of the twentieth century. Social Cosmos - URN:NBN:NL:UI:10-1-114217

Treasury Board of Canada Secretariat. (2006). Professional ethics and standards for the evaluation community in the Government of Canada. Retrieved from website: http://www.tbs-sct.gc.ca/cee/career-carriere/pesecgc-enpcegc/ pesecgc-enpcegc-eng.pdf

Turner, D. 2003. Evaluation Ethics and Quality: Results of a Survey of Australasian Evaluation Society Members, Australasian Evaluation Society, Retrieved November 2011 from http://aes.asn.au/about/Documents\%20-\%20ongoing/ ethics_survey_summary.pdf.

Van den Hoonard, E. W. C. (2013, October). Are We Asked to 'Other' Ourselves?: Social Scientists and the Research Ethics Review Process. In Academy of Social Sciences (Ed.), Generic Ethics Principles in Social Science Research, [Professional Briefings], Issue 03, (pp. 23-28). London, UK: Academy of Social Sciences.

Wiles, R., Heath, S., Crow, G., \& Charles, V. (2005). Informed Consent in Social Research: A Literature Review. NCRM Methods Paper Series 001, ESRC National Centre for Research Methods.

Wiles, R., Crow, G., Charles, V., \& Heath, S. (2007). Informed Consent and the Research Process: Following Rules or Striking Balances? Sociological Research Online 12(2). doi:10.5153/sro.1208 
Williams, E., Guenther, J., \& Arnott, A. (2011). Beyond informed consent: how is it possible to ethically evaluate Indigenous programs? Paper presented at the NARU Public Seminar Series, Darwin.

Wynn, L., White, K., Thomson, C., \& Israel, M. (2013) 'The Expanding Disciplinary Scope of Research Ethics Committees - An Inquiry into Need \& Resistance'. Macquarie University ex ARC Discovery Project.

World Medical Association. (2013). Declaration of Helsinki - Ethical Principles for Medical Research Involving Human Subjects. Retrieved from http://www.wma. net/en/30publications/10policies/b

Zimmerman, S. (2013, October). Summary of Symposium 3. In Academy of Social Sciences (Ed.), Generic Ethics Principles in Social Science Research, [Professional Briefings] Issue 03, (pp. 44-45). London, UK: Academy of Social Sciences. 